\title{
COMBATE A LA CORRUPCIÓN Y PROCEDIMIENTO ADMINISTRATIVO: UN ESPACIO DE PREVENCIÓN, SANCIÓN Y CONTROL
}

\author{
Fighting corruption and administrative proceedings: \\ Space of prevention, sanction and control
}

Geovani Ernesto MARTÍNEZ NIEVES ${ }^{2}$

Alina del Carmen NETTEL BARRERA ${ }^{2}$ Jorge SERRANO CEBALLOS

\section{Sumario:}

I. Introducción: La corrupción en el ejercicio de potestades administrativas II. Corrupción, ética pública y códigos de conducta en el control de la inactividad administrativa III. El carácter autónomo del sistema de responsabilidad disciplinaria en el Derecho mexicano IV. Recapitulación: El análisis global de la corrupción bajo el régimen jurídico procedimental.

Resumen: El trabajo aborda el tema del combate a la corrupción, tras la reciente reforma constitucional en la materia, desde la perspectiva del procedimiento administrativo como medio de control preventivo, a través de los estándares de actuación de los servidores y funcionarios públicos, así como represivo, respecto de los procedimientos de responsabilidad disciplinaria asociada a las consecuencias de la ausencia de procedimiento.

Palabras clave: Corrupción, Derecho administrativo, Procedimiento, Responsabilidad disciplinaria, Funcionarios públicos, inactividad administrativa

Abstract: The paper approach the issue of fighting corruption, following the recent constitutional reform in this area, from the perspective of the administrative proceeding as a mean of preventive control, through the standards of public officials, as well as repressive, about disciplinary responsibilities associate with the consequences of absence in administrative proceedings.

Key words: Corruption, Administrative law, Proceedings, Disciplinary responsibilities, Public officials, Inactivity of public administration.

\section{INTRODUCCIÓN: LA CORRUPCIÓN EN EL EJERCICIO DE POTESTADES ADMINISTRATIVAS}

El derecho administrativo, como marco de actuación de las Administraciones públicas, es el ámbito natural para la construcción de una auténtica cruzada en el combate a la corrup-

\footnotetext{
${ }^{1}$ Profesor de la Facultad de Derecho de la Universidad Autónoma de Querétaro.

${ }^{2}$ Profesora investigadora de la Facultad de Derecho de la Universidad Autónoma de Querétaro, miembro del grupo colegiado "Derechos humanos y globalización".

${ }^{3}$ Profesor investigador de la Facultad de Derecho de la Universidad Autónoma de Querétaro, miembro del grupo colegiado "Derechos humanos y globalización".
} 
ción. De ahí que la reforma constitucional en esta materia publicada el 27 de mayo de 2015 modifica diversos artículos que abordan el régimen jurídico de control administrativo y jurisdiccional de actuación administrativa. El régimen jurídico administrativo concreta las políticas públicas y se adelanta a un sistema represivo penal, por lo que encuentra una posición privilegiada. El trabajo que se presenta a continuación tiene dos objetivos, primero, analizar el régimen jurídico-administrativista de los códigos de conducta asociados a la procuración del procedimiento administrativo y segundo analizar el fenómeno de la corrupción en el ámbito de las potestades administrativas, particularmente, desde la perspectiva de la ausencia de este ejercicio en el procedimiento, es decir, desde la inactividad administrativa que provee un provecho particular de los servidores públicos en detrimento de los fines que debe regir el desempeño de sus funciones, el interés general. Se utiliza el método del derecho comparado con la finalidad de observar los mecanismos de control que otros países han desarrollado para encuadrar en estándares jurídicos la actuación administrativa de tal suerte que favorezca la mejor comprensión del estudio.

El trabajo parte de reconocer que desde la ciencia de la administración se ha puesto de manifiesto que la corrupción se desenvuelve ante espacios de control monopólico de las decisiones, de un elevado grado de discrecionalidad del sujeto que toma las decisiones y de una escaza responsabilidad sobre éstas. Ejemplos de este supuesto encontramos cotidianamente en la administración pública: La actividad de ordenación a través de la figura de las autorizaciones administrativas o las licitaciones para suministro, obra, arrendamientos, etcétera y todos estos supuestos tienen como común denominador que deben emitirse a través de un procedimiento. En este ámbito, el monopolio de la decisión juega un papel esencial que exige construir esquemas preventivos en la organización y funcionamiento de las Administraciones públicas como un medio eficiente de mayor alcance que las vías represivas. En este sentido, el Derecho administrativo es el espacio natural para luchar eficazmente contra la corrupción. Se reconoce que las políticas económicas y públicas juegan un papel trascendental para la planeación estratégica en materia de combate a la corrupción pero se apuesta por un modelo jurídico administrativo que permitirá alcanzar y consolidar el terreno ganado a la corrupción a través de un control procedimental. En el campo del Derecho administrativo encontramos el lugar más adecuado para diseñar las reglas del juego en el que se tutelan los intereses generales. Por una parte, los aspectos procedimentales y la transparencia en la forma de actuación de la Administración pública son muy importantes $\mathrm{y}$, por otro, la problemática debe ser abordada desde la perspectiva de control del servidor o funcionario público, de quienes dependen los intereses que concurren al procedimiento. Todas estas cuestiones representan la base de un análisis global de la corrupción en relación a un modelo normativo de carácter preventivo.

II. CORRUPCIÓN, ÉTICA PÚBLICA Y CÓDIGOS DE CONDUCTA EN EL CONTROL DE LA INACTIVIDAD ADMINISTRATIVA

Las investigaciones en materia de gestión administrativa aportan un elemento esencial para la configuración de las estrategias jurídicas en la lucha contra la corrupción, sin embargo, en general, se abordan los códigos de conducta como instrumentos de prevención que no se asocian necesariamente a códigos disciplinarios. En este sentido, la fracción III de la nueva redacción del artículo 113 de la Constitución mexicana encomienda al Comité Coordinador 
del Sistema Nacional Anticorrupción "el diseño y promoción de políticas integrales en materia de fiscalización y control de recursos públicos, de prevención, control y disuasión de faltas administrativas y hechos de corrupción, en especial sobre las causas que los generan". Las leyes secundarias tienen la extraordinaria posibilidad, a partir de esta fracción, de desarrollar parámetros de promoción del procedimiento administrativo como cauce natural de una buena gestión administrativista.

Los códigos de conducta en relación al procedimiento administrativo pueden estar presentes en dos diversas manifestaciones, a través de catálogos de deberes deontológicos o bien a través del marco normativo de los derechos y deberes de los servidores y funcionarios públicos con una serie de consecuencias en caso de incumplimiento, uno y otro modelo responden a la tradición socio-jurídica de cada país. ${ }^{4}$ Por ejemplo, el código de conducta previsto en España en el Estatuto Básico del Empleado Público5 (Ley 7/2007 de 12 de abril, en adelante EBEP) recoge ante todo, un conjunto de principios y reglas que informarán la interpretación y aplicación del régimen disciplinario de los empleados públicos y que no sólo interactúan con la procedibilidad de un procedimiento de responsabilidad disciplinaria, imprimiéndole agilidad y eficacia, sino que, con un objetivo más amplio, el Informe de la Comisión de Expertos del EBEP señala que este código tiene como finalidad "fortalecer las relaciones e incrementar la confianza entre las instituciones públicas y los ciudadanos" además "la aplicación de tales códigos de conducta puede garantizar un mejor servicio a los ciudadanos y representar un factor adicional de competitividad, clave de toda sociedad moderna". ${ }^{6}$ El establecimientos de códigos de conducta, incentivados en gran medida por las grandes instituciones internacionales como la OCDE o la Comisión Europea, en términos generales, han tenido una buena aceptación entre la doctrina, ${ }^{7}$ sin embargo, también se ha cuestionado su éxito "No deja de ser significativo, de todas formas, que este fervor por los

${ }^{4}$ Los catálogos de deberes deontológicos son "objeto de sistemas de autocontrol o de control corporativo o asociativo", así lo señala el Informe de la Comisión para el estudio y preparación del EBEP, de 25 de abril de 2005, disponible en: http://www.mpr.es/funcion_publica/estatutobasico/estatuto_funcion_publica/proceso. html.

Como ya se ha puesto de relieve por V. AGUADO y P. CAMINO, "la regulación de los deberes de los funcionarios siempre ha estado basado en valores, algunos de los cuales son valores éticos, pero no todos". Su articulación con la vía punitiva debe ser debidamente evaluada pues los códigos de conducta no pueden constituir siempre, en caso de incumplimiento una infracción disciplinaria pues desvirtuarían su auténtica función deontológica y afectarían la esencia del derecho sancionador. Por el contrario, afirman los autores, se "necesita potenciar otros mecanismos que permitan conseguir el efectivo cumplimiento de los deberes establecidos por la legislación aplicable", AGUADO I CUDOLÀ, Vicenç y CAMINO PONS, Pere. "El codi de conducta i el règim disciplinari a l'Estatut Basic de l'Empleat Públic i el seu desplegament a la legislació catalana de funció pública" en Comentaris al règim estatutari dels empleats públics, Escola d'Administració pública de Catalunya, Barcelona, 2009, p. 174-175.

5 Sobre el desarrollo normativo del Estatuto, véase, MALARET I GARCIA, Elisenda, "L'Estatut bàsic de l'empleat públic: un marc legal coherent amb l'Estat autonòmic, una caixa d'eines per a la modernització administrativa", en Comentaris al règim estatutari dels empleats públics, Escola d'Administració pública de Catalunya, Barcelona, 2009, p. 27.

${ }^{6}$ Por su parte, la Exposición de Motivos del EBEP identifica en el código de conducta y los deberes de los servidores públicos, los valores propios del servicio público una cultura de lo público que se debe mantener y tutelar en armonía con las demandas de mayor eficiencia y productividad.

7 Con sus excepciones, específicamente respecto el código de conducta del EBEP algún autor ha señalado su desconcierto por el carácter moral de los postulados, véase, PARADA VÁZQUEZ, Ramón, "Derecho del empleo público", Marcial Pons, Madrid, 2007, p. 198 y ss. En términos generales se cuestiona su "limitada eficacia especialmente en materia disciplinaria", la posible desigualdad territorial en la tipificación de las faltas disciplinarias tras su desarrollo autonómico y su "efectividad como criterio de valoración del trabajo 
códigos éticos o de buen gobierno se produzca a la par que la corrupción política campa cada vez más a sus anchas" pero es importante señalar que puede existir confusión en los resultados de evaluación de la medida adoptada al existir otros fenómenos que tienen injerencia en el problema que se pretende abordar. Ciertamente en los últimos años la corrupción se ha afianzado como "el fenómeno" a combatir para toda sociedad que pretenda alcanzar un desarrollo económico. Pero debemos reconocer que éste no es un fenómeno nuevo, por el contrario, simplemente ha alcanzado niveles inusitados exactamente igual que lo ha hecho la economía tras la globalización y ambos fenómenos están íntimamente relacionados. Los códigos de conducta siguen a la regulación de ciertos sectores económicos como la corrupción a la economía. ${ }^{9}$ De hecho la corrupción es un tema que ocupa un lugar importante para las grandes organizaciones económicas internacionales como la OCDE, FMI, BM o inclusive la ONU. ${ }^{10}$ Sin perjuicio de la importancia que tiene el Informe Nolan, encargado por el Gobierno Británico, es a través de estas organizaciones, y sus recomendaciones, que los códigos de conducta han tomado un papel de primer orden. En realidad no se trata de que los códigos de conducta coincidan con la exacerbación de la corrupción, cuestionándose su eficacia, sino que aquélla se ha combatido a través de las grandes instituciones económicas que con el alcance de sus comunicaciones y programas han llamado la atención sobre los códigos de conducta y de buen gobierno.

Los códigos de conducta deben caracterizarse por ser factibles. ${ }^{11}$ Incluso en ocasiones en las que tradicionalmente se relativiza la capacidad de actuación administrativa, por ejemplo frente a la obligación de resolver el procedimiento administrativo pues su configuración habría de estar directamente relacionada con la responsabilidad disciplinaria derivada de su incumplimiento. La previsión de una determinada obligación, su incumplimiento y poner

funcionarial a los efectos del progreso en la carrera", al respecto CARRO FERNÁNDEZ-VALMAYOR, José Luis, "Ética pública y normativa administrativa", Revista de Administración Pública, no. 181, 2010, pp. 20-22.

8 FERNÁNDEZ FARRERES, Germán, "Los códigos de buen gobierno de las Administraciones públicas", Administración y ciudadanía: Revista de la Escuela Gallega de Administración pública, Vol. 2, no. 2, 2007, p. 28 y 35.

9 Un ejemplo de esto es la regulación de los códigos de conducta en el ámbito privado tras la Directiva 2000/31/ CE del Parlamento europeo y del Consejo relativa a determinados aspectos jurídicos de los servicios de la sociedad de la información que inspiró a la Ley 34/2002, de 11 de junio, de Servicios de la Sociedad de la Información y de Comercio Electrónico. El carácter que estas normas imprimieron en la concepción de los códigos de conducta inclusive dieron lugar a su consideración como fuentes del derecho, como costumbre. MALUQUER DE MONTES BERNET, Carlos J.,"Los códigos de conducta como fuentes del derecho", Derecho privado y Constitución, no. 17, 2003, p. 374.

${ }^{10}$ Pueden visitarse los siguientes enlaces: OCDE. http://www.oecd.org/document/33/o,3343, en_2649_34857_36437537_1_1_1_1,oo.html; FMI. http://www.imf.org/external/np/exr/facts/spa/govs. htm;BM.http://web.worldbank.org/WBSITE/EXTERNAL/BANCOMUNDIAL/EXTAPRENDIZAJE/EX TWBIGOVANTCORINSPA/o,,menuPK:1745481 pagePK:64168427 piPK:64168435 theSitePK:1745286,oo. html;

México ha suscrito tres Convenciones Internacionales: La Convención Interamericana contra la Corrupción de la Organización de los Estados Americanos (1996), la Convención para Combatir el Cohecho de los Servidores Públicos Extranjeros en Transacciones Comerciales Internacionales de la OCDE (1997, aprobado por el Senado en 1999) y la Convención de las Naciones Unidas contra la Corrupción conocida como la Convención Mérida (2003). Así mismo, en el Plan Ejecutivo Conjunto de la Asociación Estratégica México Unión Europea, de 16 de mayo de 2010, se aborda como un asunto multilateral a tratar fortaleciendo la coordinación y la cooperación en el marco de la Convención de Mérida.

${ }^{11}$ VILLORIA MENDIETA, Manuel, "Evaluación de las políticas y prácticas sobre los conflictos de intereses: un informe comparativo", Administración y Ciudadanía: Revista de Escola Galega de Administración Pública, Vol. 1, no. 1, 2006, p. 223. 
en marcha los mecanismos de reacción deben constituir una ecuación funcional. A pesar del escepticismo latente sobre la eficacia de los códigos de conducta, si estos se relacionan con precisión a determinadas obligaciones previstas en el ordenamiento, el deber ser y el ser encuentran un punto de conciliación "es verdad que la legalidad no agota la moralidad, pero no lo es menos que solo (sic) cabe hablar de deontología y de 'virtudes funcionariales' en un marco de estricta observancia de la legalidad, de una rigurosa observancia general". ${ }^{12}$ Un ejemplo lo encontramos en el artículo 53.10 del EBEP ya comentado sobre principios éticos que establece sobre los empleados públicos: Cumplirán con diligencia las tareas que les correspondan o se les encomienden y, en su caso, resolverán dentro del plazo los procedimientos o expedientes de su competencia. En este caso me pregunto ¿es necesario que la redacción de un código de conducta sea recordatorio de una responsabilidad ya prevista en el ordenamiento vigente sobre los plazos para resolver. En todo caso, el hecho de que se les recuerde que deben resolver el asunto o expediente con diligencia sí forma parte de este código de conducta y la utilización de un baremo de diligencia será esencial en la determinación de responsabilidad patrimonial de la Administración por ejemplo, en caso que el retraso del expediente tenga consecuencias indemnizables.

El reto que supone combatir la corrupción de las Administraciones públicas de ciertos países -en donde el fenómeno está profundamente enraizado- implica plantear la importancia de los códigos de conducta desde su doble vertiente, deontológica y demarco referencial para la determinación de infracciones disciplinarias. Es indispensable abordar la temática desde esta perspectiva, por desgracia, el gobierno federal de México no ha tenido una política coherente en este aspecto. El Programa Nacional de Combate a la Corrupción (México 2000-2006) había previsto la adopción de un enfoque preventivo que no se llegó a consolidar. En efecto, como han puesto de manifiesto las investigaciones al respecto, el seguimiento de la puesta en marcha del Programa y de las mismas declaraciones del ahora ex presidente de la República en el Sexto Informe de Gobierno simplemente "no se informa de acciones de capacitación o mejoramiento de la ética de los servidores derivada de la redacción y publicación de códigos de ética"13 y tampoco se informa sobre el número de entidades que adoptaron el Código de Ética de la Administración Pública Federal previsto en su momento.

El Código de Ética de los Servidores Públicos de la Administración Pública Federal tiene origen en el artículo 49 de la Ley Federal de Responsabilidades Administrativas de los Servidores Públicos el cual prevé la emisión de un Código de Ética que contendrá reglas claras para que, en la actuación de los servidores públicos, impere invariablemente una conducta que responda a las necesidades de la sociedad y que oriente su desempeño en situaciones específicas que se les presenten, propiciando así una plena vocación de servicio público en beneficio de la colectividad. Además se señala que dicho Código deberá hacerse del conocimiento de los servidores públicos de la dependencia o entidad de que se trate. Al respecto debe decirse que las reglas claras a las que alude el artículo 49 se traducen en parcas explicaciones de 12 principios morales que, sin ninguna otra medida adicional, difícilmente logarán fortalecer una conducta aceptable en términos del Código. Estos principios a los que alude el Código de Conducta son: bien común, integridad, honradez, imparcialidad, justicia, trans-

\footnotetext{
${ }^{12}$ FERNÁNDEZ FARRERES, Germán, “Los códigos de buen gobierno (...)”, op. cit., p. 36.

13 SERRANO SÁNCHEZ, Jesús Antonio, "La política oficial de combate a la corrupción en México: una revisión”, Andamios, Vol. 6, no. 12, 2009, pp. 216-220.
} 
parencia, rendición de cuentas, entorno cultural y ecológico, generosidad, igualdad, respeto y liderazgo.

En su momento el legislador adoptó como medio preventivo y para intentar "asegurar" el cumplimiento de los principios y obligaciones contenidas en la Ley "establecer acciones permanentes para delimitar las conductas que en situaciones especificas deberán observar éstos (los servidores públicos) en el desempeño de sus empleos, cargos o comisiones". La propia redacción del artículo no ayuda a tener certeza si se trata de una delimitación de conductas negativas (asumo, si se trata de delimitarles, restringirlas) como por ejemplo rechazar el ofrecimiento de dádivas, o si por el contrario se trata de propia reglamentación de la actividad administrativa, lo que no supondría ninguna novedad sino se hace explícita la obligación de dejar constancia de la transparencia en la toma de decisiones a través del procedimiento administrativo. En este sentido esperamos que el legislador adopte las medidas necesarias en la legislación secundaria tras la reforma constitucional de 2015.

En el derecho mexicano, la conducta de los servidores públicos respecto del procedimiento administrativo principalmente podrá ser analizada desde la perspectiva de los instrumentos de represión y sólo tangencialmente. Así, la Ley Federal de Responsabilidades Administrativa de los Servidores Públicos, en el artículo 8 titulado Obligaciones de todo servidor público señala en su última fracción que estos deberán abstenerse de cualquier acto u omisión que implique incumplimiento de cualquier disposición legal, reglamentaria o administrativa relacionada con el servicio. Sin perjuicio de la interpretación restringida que se pueda hacer del concepto de servicio público, esta fracción podría habilitar para que el artículo 16 de la Ley Federal de Procedimiento Administrativo se considerara título de imputación de responsabilidad por el incumplimiento de la fracción X de dicho artículo dictar resolución expresa sobre cuantas peticiones le formulen; así como en los procedimientos iniciados de oficio; cuya instrucción y resolución afecte a terceros, debiendo dictarla dentro de los plazos fijados por la ley. Llama la atención que, tratándose del fortalecimiento de códigos de conducta de los servidores este artículo exente de la obligación de resolver procedimientos iniciados de oficio cuando no existen terceros perjudicados ¿y el interés general? El primero de los principios indicados en el Código de Ética de los Servidores Públicos queda totalmente desvirtuado. Para llegar a esta conclusión sólo basta conocer de la excepción y relacionarla con la definición de bien común que hace el Código: todas las decisiones y acciones del servidor público deben estar dirigidas a la satisfacción de las necesidades e intereses de la sociedad, por encima de los intereses particulares ajenos al bienestar de la colectividad. El compromiso con el bien común implica que el servidor público esté consciente de que el servicio público es un patrimonio que pertenece a todos los mexicanos y que representa una misión que sólo adquiere legitimidad cuando busca satisfacer las demandas sociales y no cuando se persiguen beneficios individuales. Qué ironía tan grande que por un lado se le conmine al servidor público a servir a los intereses generales y por otro se le exima de responsabilidad si un procedimiento no implica a ningún otro interés que el interés general.

Si bien la ausencia de procedimiento administrativo no ha sido abordada directamente por los tribunales mexicanos para pronunciarse sobre los principios que deben regir en la actuación administrativa, ciertamente sí se ha admitido la importancia del procedimiento y de sus elementos en el control de actividades irregulares de los órganos administrativos. En este sentido, la tesis aislada que se señala a continuación reconoce la trascendencia del muestreo de mercancías como acto que da inicio a determinado procedimiento aduanero 
lo que coadyuvará a la transparencia en este difícil ámbito administrativo desde el punto de vista de la corrupción.

"ACTA DE MUESTREO DE MERCANCÍAS DE DIFÍCIL IDENTIFICACIÓN. FORMA PARTE DEL PROCEDIMIENTO ADMINISTRATIVO EN MATERIA ADUANERA, AL CONSTITUIR UNA CONDICIÓN PREVIA INDISPENSABLE PARA SU INICIO EN LOS CASOS EN QUE EXISTAN IRREGULARIDADES EN LA CLASIFICACIÓN ARANCELARIA. Si bien es cierto que el acta de muestreo de mercancías de difícil identificación prevista en la Ley Aduanera, por su naturaleza, no tiene por objeto establecer y asentar alguna irregularidad, también lo es que constituye una condición previa indispensable para el inicio del procedimiento administrativo en materia aduanera en los casos en que existan irregularidades en la clasificación arancelaria, por lo que forma parte de éste, pues si como resultado de la toma de muestras la autoridad determina que el producto analizado no se ubicó en la fracción arancelaria pertinente, tal irregularidad da inicio al procedimiento administrativo en materia aduanera, al actualizarse una facultad reglada para la administración, que necesariamente culmina con el dictado de una resolución que impone un crédito fiscal por el adeudo resultante de la incorrecta clasificación”. ${ }^{14}$

No es precisamente abundante la jurisprudencia sobre las garantías del procedimiento en materia de transparencia y combate a la corrupción, pues como ya he tenido oportunidad de señalar, ésta se ha llevado a cabo tradicionalmente a través de mecanismos represivos en el ámbito del Derecho penal. De manera parcial se ha abordado el procedimiento desde las garantías del interesado en el cumplimiento del Derecho de petición, en este sentido "La Suprema Corte también ha sustentado el criterio que, en los casos en que deben desahogarse diversos trámites con motivo de la petición, el peticionario debe ser informado respecto de los acuerdos sucesivos que se vayan tomando y, en su caso, de las omisiones que deba subsanar para que los trámites continúen". ${ }^{15}$ Desde un punto de vista pragmático se propone revalorizar el procedimiento administrativo como instrumento de contención de prácticas corruptas en base a este tipo de criterios aprovechando la trascendencia del derecho de petición en el ordenamiento jurídico mexicano.

II. EL CARÁCTER AUTÓNOMO DEL SISTEMA DE RESPONSABILIDAD DISCIPLINARIA EN EL DERECHO MEXICANO

La pasividad del personal al servicio de las Administraciones públicas en el ámbito procedimental y en consecuencia, la producción del silencio administrativo no sólo implica la vulneración del derecho de petición consagrado en el artículo $8^{\circ}$ de la Constitución mexicana sino también la contravención al ordenamiento administrativo lo que exige la imputación

\footnotetext{
${ }^{14}$ CUARTO TRIBUNAL COLEGIAdO EN MATERIA ADMINISTRATIVA DEL PRIMER CIRCUITO. Revisión fiscal 62/2010. Administrador de lo Contencioso " 5 ", en suplencia por ausencia del Administrador Central de lo Contencioso y de los Administradores de lo Contencioso " 1 ", "2", " 3 " y " 4 " de la Administración Central de lo Contencioso del Servicio de Administración Tributaria. 8 de julio de 2010. Unanimidad de votos. Ponente: Jean Claude Tron Petit. Secretario: Marco Antonio Pérez Meza. Véase, tesis aislada, 9a. Época; T.C.C.; S.J.F. y su Gaceta; XXXIII, Febrero de 2011; p. 2242.

${ }^{15}$ ANDRADE S. Eduardo, "Artículo $8^{\circ}$ Constitucional", Derechos del pueblo mexicano, México a través de sus constituciones, H. Cámara de Diputados, Tomo II, México, 1985, p. 909.
} 
de una responsabilidad de carácter disciplinario. ${ }^{16}$ Resulta imprescindible insistir en la importancia de incoar los procedimientos disciplinarios que correspondan contra el personal encargado del procedimiento pues éste no puede excusarse de resolver las instancias de los particulares ni siquiera bajo pretexto de incapacidad de medios. La responsabilidad disciplinaria de los servidores públicos se hace indispensable en el control de la inactividad administrativa, tanto material como procedimental pero en el contexto de la vulneración del derecho fundamental de petición, cobra una importancia trascendental.

Se debe poner de manifiesto que, como ha señalado H. TORRES ULLOA, "El régimen jurídico de los servidores públicos reclama el desarrollo de actividades no sólo con eficacia, sino con estricto apego al conjunto de normas jurídicas federales, estatales y municipales que deben cumplirse ${ }^{\prime 17}$ en este sentido, la pasividad procedimental y la correlativa vulneración del derecho de petición constitucional no encuentra justificación alguna.

Tradicionalmente en México, se han estudiado cinco tipos de responsabilidades en las que puede incurrir un servidor público, civil, penal, administrativa, política y la constitucional, esta última se deriva del incumplimiento de las sentencias de amparo y de la Suprema Corte de Justicia de la Nación en materia de controversias constitucionales y acciones de inconstitucionalidad..$^{18}$ Por lo que corresponde a la responsabilidad administrativa, específicamente la responsabilidad disciplinaria, se entiende que ésta se desprende de la relación jerárquica que se establece en toda organización pública. A efectos metodológicos, por ahora se abordará exclusivamente la responsabilidad de los servidores públicos del Poder Ejecutivo, dejando a un lado la responsabilidad que pudiera corresponder a los jueces y magistrados y de los senadores y diputados del Poder Legislativo. Lo anterior sin perjuicio de poner de manifiesto que la Ley Federal de Responsabilidades de los Servidores Públicos, tiene carácter de norma reglamentaria del Título Cuarto de la Constitución "De las responsabilidades de los servidores públicos y patrimonial del Estado" por lo que respecto de los primeros, abarca tanto la responsabilidad política como la estrictamente administrativa o disciplinaria.

El marco normativo de la responsabilidad disciplinaria comienza en la propia Constitución mexicana, consolidándose tras la reciente reforma. El artículo 73 XXIX-H modifica la denominación del Tribunal Federal de Justicia Administrativa (antes Tribunal Federal de Justicia Fiscal y Administrativa) y habilita para "imponer sanciones a los servidores públicos por responsabilidad administrativa que la ley determine como graves y a los particulares que participen en actos vinculados con dichas responsabilidades". Sobre el control jurisdiccional de las sanciones impuestas a los servidores públicos, la regulación actual tiene como ante-

\footnotetext{
${ }^{16}$ En este trabajo se hace referencia a la responsabilidad disciplinaria en el contexto del ejercicio de potestades administrativas. No obstante, un sector de la doctrina mexicana ha señalado que la responsabilidad administrativa se distingue de la disciplinaria por el bien jurídico protegido. En el primer caso se protege el patrimonio o bienes de las Administraciones y se dirige a servidores públicos y sujetos privados por igual y la segunda tutela el adecuado cumplimiento de la función pública por parte del personal. Bajo este panorama la imposición de una sanción pecuniaria a través del procedimiento disciplinario es independiente de la responsabilidad extracontractual que pudiera exigir la Administración por un daño o perjuicio a su patrimonio o de la responsabilidad civil derivada de un ilícito penal. Al respecto véase, BURRUEL HUERTA, Leopoldo, La responsabilidad del Estado y sus agentes, Porrúa-ELD, México, 2009, p. 75.

${ }^{17}$ TORRES ULLOA, Héctor Samuel, "Responsabilidades de los servidores público. Su situación actual y perspectivas", Revista de los Tribunales Agrarios, 2a época, Año IV, No. 41, enero-abril de 2007, p. 55.

${ }^{18}$ Sin embargo ésta última normalmente pasa desapercibida, en este sentido se pronuncia MÁRQUEZ RÁBAGO, Sergio R., "Los tipos de responsabilidad del servidor público y la responsabilidad constitucional, en Lex, Difusión y análisis, Cuarta época, Año, XV, No. 183, septiembre de 2010, pp. 35 y 36.
} 
cedente más próximo la reforma de 200619 sistema no exento de controversia pues durante algún tiempo se consideró que la regulación inicial de la Ley Federal de Responsabilidades Administrativas facultada a la Administración para imponer una sanción sin las garantías mínimas jurisdiccionales que establece la propia Constitución. ${ }^{20}$ Con el reconocimiento del

${ }^{19}$ Reforma del artículo 73 XXIX-H de la CPEUM por Decreto publicado en el Diario Oficial de la Federación
el 4 de diciembre de 2006 . La reforma no estuvo exenta de controversia, si bien el texto literal de la fracción
XXIX-H del artículo 73 se refiere a otorgar competencia a los tribunales de lo contencioso administrativo,
la Exposición de Motivos de dicha reforma aludía a la creación de un órgano autónomo, distinto de los
tribunales y de la propia Administración sancionadora. En el 2015 la creación del Comité Coordinador del
Sistema Nacional Anticorrupción parece tener mejores perspectiva de consolidación que el modelo anterior.
Sobre la inconclusa reforma de 2006, véase, MARTÍ CAPITANACHI, Luz del Carmen, "La responsabilidad
administrativa de los servidores públicos. Reforma constitucional en proceso", Letras Jurídicas, Año 7, No. 14, julio-diciembre de 2006, p. 292.

${ }^{20}$ En este sentido se consideraba que la imposición de sanciones por parte de las autoridades administrativas vulneraba el artículo 17 de la Constitución al actuar de manera parcial, como juez y parte, en la imposición de la sanción. Sin embargo, la doctrina legal ha reconocido la competencia de los tribunales contencioso administrativos para conocer de las resoluciones en la materia permitiendo identificar la sanción administrativa como un control interno de la Administración siempre recurrible por los tribunales. SERVIDORES PÚBLICOS. EN CONTRA DE LAS RESOLUCIONES EN QUE SE LES IMPONGA ALGUNA SANCIÓN PREVISTA EN LA LEY FEDERAL RELATIVA, PREVIAMENTE AL JUICIO DE AMPARO DEBERÁN INSTAURAR JUICIO DE NULIDAD ANTE EL TRIBUNAL FEDERAL DE JUSTICIA FISCAL Y ADMINISTRATIVA. De una interpretación sistemática de lo dispuesto por los artículos 108, párrafo primero, constitucional, 20., 30., fracción III, de la Ley Federal de Responsabilidades de los Servidores Públicos, y 56 de la Ley Orgánica de la Procuraduría General de la República, se advierte que son sujetos del régimen de responsabilidades a que se refiere el título cuarto del Pacto Federal, los funcionarios, empleados y, en general, toda persona que desempeñe un cargo o comisión de cualquier naturaleza en la administración pública federal; en consecuencia, tratándose de conflictos derivados de la prestación de servicios en los que se imponga alguna o varias de las sanciones que prevé la Ley Federal de Responsabilidades de los Servidores Públicos, es inconcuso que para su impugnación, previamente al ejercicio de la acción constitucional, deberá instaurarse el juicio de nulidad ante el Tribunal Federal de Justicia Fiscal y Administrativa, conforme a los artículos 70 y 73 de esta última ley, y los diversos 10. y 11, fracción XII, párrafo segundo, de la Ley Orgánica del Tribunal Federal de Justicia Fiscal y Administrativa, toda vez que a ese órgano se le ha dotado de facultades jurisdiccionales para resolver en materia disciplinaria de los conflictos que se susciten por infracciones de responsabilidad administrativa de servidores públicos. De no observarse lo anterior, procederá el sobreseimiento en el juicio de amparo indirecto, en términos de los artículos 73, fracción XV y 74, fracción III, ambos de la Ley de Amparo; véase, 9a. Época; T.C.C.; S.J.F. y su Gaceta; XVIII, Agosto de 2003; Pág. 184. En la misma tesitura, "SERVIDORES PÚBLICOS. LA FACULTAD PARA INICIAR PROCEDIMIENTOS ADMINISTRATIVOS DE RESPONSABILIDAD E IMPONERLES SANCIONES, OTORGADA EN EL ARTÍCULO 64 DE LA LEY FEDERAL DE RESPONSABILIDADES RELATIVA A FAVOR DE LA SECRETARÍA DE LA FUNCIÓN PÚBLICA, NO LOS PRIVA DE LA GARANTÍA DE ACCESO A LA JUSTICIA PREVISTA EN EL NUMERAL 17 CONSTITUCIONAL. El citado precepto legal, al establecer que la actual Secretaría de la Función Pública es la autoridad competente para imponer sanciones administrativas a los servidores públicos, a través de un procedimiento donde se cita al presunto responsable a una audiencia para el ofrecimiento de pruebas; que debe resolver, dentro de los treinta días siguientes al desahogo de aquéllas, si es inexistente la responsabilidad, o bien imponer al infractor las sanciones respectivas; y que puede disponer la práctica de investigaciones y fijar otras audiencias en caso de no contar con elementos suficientes para hacer un pronunciamiento en relación con la responsabilidad de aquél, no contraviene el artículo 17 de la Constitución Política de los Estados Unidos Mexicanos, en cuanto al deber de toda autoridad de actuar en forma imparcial. Lo anterior es así, en virtud de que la Secretaría sólo ejerce su potestad disciplinaria, pero sus actos son revisados por los tribunales encargados de impartir justicia, lo que denota que no realiza una función jurisdiccional, sino un mero control interno de legalidad, pero además, porque la propia Ley Federal de Responsabilidades de los Servidores Públicos establece que contra las resoluciones administrativas dictadas contra éstos, podrán optar entre interponer el recurso de revocación o impugnarlas directamente ante el Tribunal Federal de Justicia Fiscal y Administrativa, lo que pone de manifiesto que no se les priva de sus 
control jurisdiccional de la potestad sancionadora y disciplinaria de las Administraciones públicas, se sientan las bases de un sistema elemental pero, por lo que se refiere a las garantías mínimas de este poder queda mucho por hacer, ${ }^{21}$ específicamente, es necesaria la formulación de un marco de infracciones administrativas ${ }^{22}$ que no sólo garantizarían una determinada objetividad del procedimiento sino que, además, determinarían un marco de referencia preciso para los servidores públicos en el desempeño de sus funciones. Íntimamente relacionado, y por lo que corresponde al tema que nos ocupa, es necesario el establecimiento de códigos de conducta que guíen el mejor desempeño de los servidores públicos.

garantías de acceso a la justicia completa e imparcial y de equidad procesal, ya que las sanciones corresponden". Véase, en 9a. Época; 2a. Sala; S.J.F. y su Gaceta; XXX, Julio de 2009; p. 469.

${ }^{21}$ Es representativa la sentencia sobre la garantía de audiencia en el procedimiento disciplinario analizado con motivo de las reformas al sistema de responsabilidad patrimonial de la Administración y su relación con la responsabilidad disciplinaria de los funcionarios o servidores públicos "RESPONSABILIDAD PATRIMONIAL DEL ESTADO. EL ARTÍCULO 392 DEL CÓDIGO FINANCIERO DEL DISTRITO FEDERAL VIGENTE EN 2004, VIOLA LA GARANTÍA DE AUDIENCIA. El citado precepto, que establece la facultad del Distrito Federal para exigir de sus servidores públicos responsables del daño causado el pago de la indemnización hecha a los particulares, mediante el procedimiento administrativo de ejecución, viola la garantía de audiencia contenida en el artículo 14 de la Constitución Política de los Estados Unidos Mexicanos, ya que no prevé un procedimiento en el cual el servidor público al que se impute la falta causante del hecho dañoso que haya dado lugar al pago de la indemnización al particular tenga oportunidad para intervenir, con la posibilidad de conocer las imputaciones que se le hagan, aportar pruebas y realizar alegatos, asegurándosele el acceso a una defensa adecuada”. Acción de inconstitucionalidad 4/2004. Diputados integrantes de la Tercera Legislatura de la Asamblea Legislativa del Distrito Federal. 7 de febrero de 2008. Unanimidad de diez votos. Ausente y Ponente: Sergio Salvador Aguirre Anguiano; en su ausencia hizo suyo el asunto Mariano Azuela Güitrón. Secretario: Eduardo Delgado Durán. El Tribunal Pleno, el doce de mayo en curso, aprobó, con el número 45/2008, la tesis jurisprudencial que antecede. México, Distrito Federal, a doce de mayo de dos mil ocho. Véase, 9a. Época; Pleno; S.J.F. y su Gaceta; XXVII, Junio de 2008, p. 721.

22 "RESPONSABILIDADES DE LOS SERVIDORES PÚBLICOS. LA APLICACIÓN DE LAS SANCIONES ADMINISTRATIVAS CORRESPONDIENTES SURGE COMO CONSECUENCIA DE SUS ACTOS U OMISIONES DEFINIDOS EN LA PROPIA LEGISLACIÓN BAJO LA CUAL SE EXPIDIÓ SU NOMBRAMIENTO, EN LA NORMATIVIDAD Y ESPECIFICACIONES DE LA ACTIVIDAD DESARROLLADA O BIEN DE LAS QUE SE CONTEMPLAN EN LA LEY FEDERAL RELATIVA. Para que un servidor público pueda ser sancionado basta que su conducta sea contraria a las obligaciones y principios que le impone la Ley Federal de Responsabilidades de los Servidores Públicos, sin que sea óbice la falta de previsión del puesto que ocupa o de algún deber en la ley de la dependencia a la que se encuentre adscrito. En efecto, la facultad disciplinaria encuentra su fundamento en el servicio público que el Estado debe prestar a la comunidad con excelencia, a fin de asegurar y controlar la calidad y continuidad de su actividad, que se instrumenta a través de las funciones, empleos, cargos y comisiones de los servidores públicos y que debe satisfacer los valores y cualidades de legalidad, honradez, lealtad, imparcialidad y eficiencia de la gestión y acción administrativa que trasciendan a la calidad y peculiaridades del servicio público para obtener los fines de la planeación y satisfacer las necesidades públicas con la mayor economía y calidad, de suerte que la administración tiene la facultad y la obligación de auto-organizarse para cumplir sus objetivos y, en ese contexto, se inscribe el poder disciplinario como actividad de control. En este orden de ideas, la responsabilidad administrativa de los servidores públicos surge como consecuencia de sus actos u omisiones, ya sea que se definan en la legislación bajo la cual se expidió su nombramiento, en la normatividad y especificaciones propias de la actividad desarrollada, o bien, de las que se contemplen en la Ley Federal de Responsabilidades de los Servidores Públicos; pues de no considerarse así, bastaría que el ordenamiento jurídico relativo a determinada dependencia del Ejecutivo, no previera en concreto y expresamente las obligaciones y deberes que a cada servidor público razonablemente le corresponden para dejar impunes prácticas contrarias a los valores y cualidades que orientan a la administración pública y garantizan el buen servicio bajo el principio unitario de coherencia entre la actuación del servidor público y valores constitucionales conducentes, sobre la base correlativa de deberes generales y exigibilidad activa de su responsabilidad"; véase, en 9a. Época; T.C.C.; S.J.F. y su Gaceta; XXIII, Mayo de 2006; Pág. 1867. 
Por otra parte, es indispensable que la legislación secundaria desarrolle las garantías procedimentales y procesales de la posible imposición de sanciones a los particulares a partir de su participación con actos vinculados a responsabilidades administrativas y actos constitutivos de corrupción. El análisis de este supuesto merece un trabajo independiente pero por ahora se debe señalar que si se apuesta por el establecimiento de códigos de conducta para los servidores públicos respecto de los ciudadanos, la exigencia de instrumentos de certeza y claridad a partir de los cuales se considere la imputación de responsabilidades debe ser mayor en el marco del debido proceso pues se le está haciendo partícipe de un régimen propio de los responsables de la actuación administrativa (sin perjuicio de la ya conocida formula de denuncia de cohecho).

Por otra parte, es significativo que la regulación de la responsabilidad administrativa de los servidores públicos, los procedimientos, recursos y el control jurisdiccional de las sanciones impuestas haya tenido un desarrollo lento en el ordenamiento mexicano ${ }^{23}$ cuando ha sido constante la existencia de Secretarías en materia de contraloría y supervisión del desempeño de la función pública. El lamentable retraso en esta materia responde a la parcialidad de los órganos encargados del control interno ya que se encuentran relacionados jerárquica y políticamente con el mismo órgano. La Secretaría de la Función Pública ha tenido históricamente, entre sus principales funciones, la fiscalización de la gestión pública a efectos tanto preventivos como sancionadores en el desempeño de las funciones que le encomienda la Ley Federal de Responsabilidades de los Servidores Públicos. Como se ha puesto de manifiesto en las propuestas de reforma del marco normativo en materia de corrupción, en la medida que las facultades de fiscalización no estén conferidas a un órgano imparcial e independiente de la propia Administración o cuando menos que tenga garantizada cierta autonomía, el sistema de control interno mexicano seguirá dejando mucho que desear. ${ }^{24}$ Todo ello quedó particularmente agudizado ante la fracasada propuesta del gobierno de subsumir la Secretaría de Seguridad Pública con la Secretaría de la Función Pública en una sola entidad, reforma orgánica que finalmente no culmina y ha tenido que esperar hasta el año 2015 para intentar sobreponerse a través de una reforma constitucional. En este sentido, la creación del Sistema Nacional Anticorrupción, el posible fortalecimiento de los órganos internos de control y de la Auditoría Superior de la Federación, la formulación de la Fiscalía Especializada en Combate a la Corrupción y la reforma a los criterios de autonomía del ahora Tribunal Federal de Justicia Administrativa parecían mejorar el panorama, por desgracia, queda pendiente dilucidar algunos aspectos que la ley secundaria deberá abordar. Como primer ejemplo se menciona el importantísimo criterio para determinar cuáles son faltas graves y cuáles no, pues de ello depende que conozca de la causa el Tribunal Federal de Justicia Administrativa o se quede en manos del órgano interno de control (párrafos cuarto y quinto de la fracción III de la nueva redacción del artículo 109 de la Constitución mexicana).

Respecto del ámbito subjetivo del sistema de responsabilidades, el concepto de servidor público en el derecho mexicano lo determina la propia Constitución en el artículo 108 "se

\footnotetext{
${ }^{23}$ DELGADILLO GUTIÉRREZ, Luis Humberto, El sistema de responsabilidades de los servidores públicos, Porrúa, México, 2005, p. 55.

${ }^{24}$ FERNÁNDEZ RUIZ, Jorge, "La dirección de responsabilidades y sanciones de la contraloría general del Departamento de Distrito Federal es autoridad de facto", Anuario Jurídico, Nueva Serie, México, 1996; MENDOZA LÓPEZ, Alberto, MORENO GARCÍA, Alfonso, ACEVO ANONALES, Dante, "Las responsabilidades administrativas de los servidores públicos”, Bien Común, Año XI, No. 125, mayo de 2005; MÁRQUEZ, GÓMEZ, Daniel, Los procedimientos administrativos materialmente jurisdiccionales como medios de control en la Administración pública, UNAM, México, 2003.
} 
reputarán como servidores públicos a los representantes de elección popular, a los miembros del poder judicial federal y del poder judicial del Distrito Federal los funcionarios y empleados $y$, en general, a toda persona que desempeñe un empleo, cargo o comisión de cualquiera naturaleza en el Congreso de la Unión, en la Asamblea legislativa del distrito Federal o en la Administración Pública Federal o en el Distrito Federal así como los servidores públicos de los organismos a los que esta Constitución otorgue autonomía, quienes serán responsables por los actos u omisiones en que incurran en el desempeño de sus respectivas funciones" este concepto amplísimo, sin embargo, no afecta los Estados de la República que, a través de sus propias Constituciones, pueden establecer a quiénes les corresponde el carácter de servidor público. La responsabilidad que puede fincarse a los sujetos que ostenten el carácter de servidor público gira en torno a las obligaciones previstas en el régimen general disciplinario. Al respecto, la Ley Federal de Responsabilidades Administrativas de los Servidores públicos, en el artículo 8, señala una serie de obligaciones25 específicas de los servidores públicos con el fin de salvaguardar los principios (artículo 7) de legalidad, honradez, lealtad, imparcialidad y eficiencia que rigen en el servicio público". ${ }^{26}$ Además prevé la incorporación en cada dependencia o entidad administrativa de una oficina de atención a través de la cual cualquier interesado podrá interponer una queja o denuncia a un servidor público a efecto de iniciar el procedimiento disciplinario correspondiente. Por otra parte, el procedimiento sancionador se regula en el Capítulo II del Título Segundo de la Ley y las sanciones que se pueden imponer son la amonestación (pública o privada), la suspensión, la destitución del puesto, sanción económica e inhabilitación temporal para desempeñar empleos, cargos o comisiones en el servicio público, artículo 13.

Con motivo de la reforma del sistema de responsabilidad patrimonial de las Administraciones públicas mexicanas, cuando la actividad u omisión del servidor público haya causado una lesión indemnizable, el ciudadano que la padezca, podrá reclamar el pago directamente, es decir, podrá exigir a la Administración la indemnización con independencia del procedimiento sancionador que se pueda instruir en contra del servidor público. Sin embargo, esto no siempre ha sido así pues el sistema anterior basado en el Código Civil para el Distrito Federal y para toda la República en materia federal reconocía una responsabilidad solidaria entre Administraciones públicas y servidores públicos cuando se tratara de actos ilícitos dolosos y subsidiaria en los demás casos, exigiéndose que primero se reclamara la indemnización al servidor público y, sólo en caso de que este último no pudiera satisfacerlo, se podría reclamar el pago al Estado. ${ }^{27}$ Por otro lado, la Ley de Responsabilidades de los Servidores Públicos reconoce, en el artículo 77-BIS, vigente en esta materia en el Distrito Federal, que tras un procedimiento de carácter disciplinario que admita la responsabilidad de un determinado servidor público (y también la existencia de daños y perjuicios) los ciudadanos podrán reclamar en vía administrativa, a la propia Administración o a la Secretaría de la Función Pública para que se gestione la indemnización. En este contexto se debe tener presente que en la reforma del sistema de responsabilidad patrimonial del Estado o de las Administraciones públicas concretamente, la Constitución mexicana reconoce un auténtico

\footnotetext{
${ }^{25}$ Un análisis pormenorizado de las obligaciones de los servidores públicos puede encontrarse en BURRUEL HUERTA, Leopoldo, "La responsabilidad del Estado (...)", op. cit. p.118 y ss.

${ }^{26}$ La Ley de Responsabilidad de los Servidores Públicos, vigente en el Distrito Federal, en el artículo 47, agrega que estos principios "deben ser observadas en el desempeño de su empleo, cargo o comisión, y cuyo incumplimiento dará lugar al procedimiento y a las sanciones que correspondan".

${ }^{27}$ FERNÁNDEZ RUIZ, Jorge. "Panorama del Derecho mexicano. Derecho Administrativo", UNAM-McGrawHill, México, 1997, pp, 172-176.
} 
carácter directo de responsabilidad. Hasta antes de la modificación la posibilidad de exigir en vía administrativa la indemnización, sólo podía ser tras la determinación de una responsabilidad disciplinaria del servidor público, es decir, no era de carácter directo ya que estaba supeditado a que se hubiere fincado responsabilidad al servidor público.

El sistema de responsabilidad indirecta que parece haber sido superado desde la perspectiva de la responsabilidad extracontractual de las Administraciones públicas ha determinado una vinculación interesante entre ambos tipos de responsabilidad en el Distrito Federal, pues su carácter autónomo no ha inhabilitado la vía de indemnización en caso de determinarse la responsabilidad de un servidor público en el ejercicio de sus funciones. En esta dinámica parece funcional la relación entre la garantía patrimonial consagrada inicialmente en el artículo 113 de la Constitución (109 a partir de la entrada en vigor de las leyes generales previstas con la reforma de 2015) a través de la responsabilidad de carácter objetivo y directo y el control de la actividad e inactividad administrativa. Sin embargo, resulta inquietante la tesis aislada del Tribunal Colegiado Auxiliar con sede en Naucalpan, Estado de México (esta entidad federativa mantiene una normativa semejante al Distrito Federal en el sentido de poder reclamar la indemnización en el procedimiento disciplinario que se instruye tras su denuncia) la cual resuelve a favor de la subsistencia de la responsabilidad disciplinaria sobre la responsabilidad directa del Estado en tanto que, siendo posible para el interesado la reclamación de indemnización de daños y perjuicios a través de la determinación de la responsabilidad del servidor público, se deberá esperar la resolución del expediente disciplinario para determinar si ha existido una actuación irregular. El tribunal confunde la actividad irregular del funcionario con la del Estado desde la perspectiva del criterio orgánico de funcionamiento de las Administraciones públicas. ${ }^{28}$

Por ahora interesa señalar que, en materia de control de la inactividad administrativa, esta vinculación no parece estar desproporcionada en la medida que mantiene un nexo funcional entre la responsabilidad del servidor público con el instituto del resarcimiento, desde el punto de vista del control de la inactividad administrativa y el correcto ejercicio de la función

\footnotetext{
${ }^{28}$ Véase, "RESPONSABILIDAD PATRIMONIAL DEL ESTADO. LOS ARTÍCULOS 117 Y 138 DEL CÓDIGO DE PROCEDIMIENTOS ADMINISTRATIVOS DEL ESTADO DE MÉXICO, AL PREVER QUE EL PAGO DE LOS DAÑOS Y PERJUICIOS SOLICITADO POR AQUÉLLA SE DETERMINARÁ HASTA QUE SE EMITA RESOLUCIÓN EN EL PROCEDIMIENTO ADMINISTRATIVO SANCIONADOR CONTRA EL SERVIDOR PÚBLICO CUYA CONDUCTA LO ORIGINÓ, NO VIOLAN EL ARTÍCULO 113 DE LA CONSTITUCIÓN FEDERAL. El artículo 113, segundo párrafo, de la Constitución Política de los Estados Unidos. (...) de los artículos 117 y 138 del Código de Procedimientos Administrativos del Estado de México se observa, por un lado, la facultad de los particulares para que al formular una denuncia o queja ante una autoridad administrativa, contra la conducta de un servidor público estatal o municipal, soliciten el pago de daños y perjuicios causados por éste y, por otro, que al emitirse la resolución sancionadora correspondiente, se determinará si procede o no el mencionado pago, debiéndose cuantificar, en su caso, el importe respectivo. De lo anterior se advierte que la finalidad del legislador ordinario al establecer en los señalados dispositivos un procedimiento para determinar la indemnización a la cual puede ser condenado el Estado, fue para comprobar que efectivamente se hubiera realizado una actividad irregular, a través del procedimiento administrativo sancionador, lo cual reúne las características de ser objetivo y constitucionalmente válido y se evita el reclamo injustificado de indemnizaciones excesivas. En estas condiciones, se concluye que los referidos artículos 117 y 138, al prever que el pago de los daños y perjuicios solicitado por la responsabilidad patrimonial del Estado se determinará hasta que se emita resolución en el procedimiento administrativo sancionador contra el servidor público cuya conducta lo originó, no violan el precepto 113 constitucional". 9a. Época; T.C.C.; S.J.F. y su Gaceta; XXXIII, Enero de 2011, p. 3260.
} 
pública, sin perjuicio de que los ciudadanos tengan garantizado el respeto a su patrimonio por la Ley de Responsabilidad Patrimonial del Estado.

Es importante señalar también que, a pesar de que tradicionalmente se ha negado la legitimación o el interés jurídico del denunciante en un procedimiento disciplinario, este criterio podría comenzar a modificarse. En este sentido se ha pronunciado G. D. GÓNGORA PIMENTEL al señalar que una interpretación coherente de la todavía vigente Ley de Responsabilidades de los Servidores Públicos (la cual sólo faculta para impugnar las resoluciones absolutorias del anterior Tribunal Federal de Justicia Fiscal y Administrativa al superior jerárquico del funcionario implicado) con los artículos 108 y 109 de la Constitución mexicana (que establecen los principios rectores de la actuación de los servidores públicos) favorece la comprensión homogénea del sistema y permite sostener que la conducta contraria al prestación adecuada del servicio público es de interés general. ${ }^{29}$ Reconocer la legitimación al denunciante permite la colaboración de los ciudadanos con las Administraciones públicas para el mejor desempeño de éstas y la consecución de los intereses generales como ya he señalado con anterioridad. Al respecto, la reforma constitucional, en el artículo 109, simplemente prevé que la Auditoría Superior de la Federación y la Secretaría del Ejecutivo Federal responsable del control interno podrán recurrir las determinaciones de la Fiscalía Especializada en Combate a la Corrupción y del Tribunal Federal de Justicia Administrativa en relación con las omisiones que impliquen no fincar responsabilidades. En cualquier caso se deja nuevamente vedada la posibilidad de intervenir a los particulares cuando les asista un interés legítimo o vean vulnerado un derecho ante los hechos constitutivos de faltas administrativas o hechos de corrupción.

III. RECAPITULACIÓN: EL ANÁLISIS GLOBAL DE LA CORRUPCIÓN BAJO EL RÉGIMEN JURÍDICO PROCEDIMENTAL

El panorama que se ha presentado responde a la necesidad de construir un auténtico modelo de referencia para los servidores y funcionarios públicos en el desempeño de sus funciones, un sistema que recupere el valor del procedimiento como institución autónoma, vigente y eficiente para solventar las exigencias del trabajo de las Administraciones públicas. Por otra parte, la propuesta recoge la importancia de la responsabilidad administrativa ante la pasividad del servidor público y las consecuencias perjudiciales para el combate a la corrupción. No se trata de regresar a la idealización de un modelo represivo sino todo lo contrario, de poner énfasis en los aspectos preventivos, específicamente en los mensajes que el propio ordenamiento envía a los empleados públicos. Es indispensable que estos sepan cuáles serán las consecuencias de un actuar irregular frente al procedimiento administrativo que ha de ser testigo de un desempeño adecuado. En este sentido la reforma constitucional de 2015 no parece percatarse de la oportunidad de establecer reglas precisas sobre la autonomía de los órganos internos de control que continúan monopolizando las faltas no graves y sobre la trascendencia del procedimiento para el control de este tipo de faltas. La leyes generales que deberán concretar la reforma determinarán el impacto que ésta tenga finalmente y se

\footnotetext{
${ }^{29}$ GÓNGORA PIMENTEL, Genaro David, "El afectado en forma directa o indirecta por la conducta del servidor público respecto de quien haya interpuesto queja administrativa, tiene interés jurídico para promover juicio de amparo contra la resolución que la declara improcedente o sin efectos para fincar su responsabilidad (a manera de propuesta)", Lex Difusión y Análisis, Año XI, No. 128, febrero de 2006, pp. 7-9.
} 
espera que superen, entre otros, los aspectos problemáticos de las leyes de responsabilidades administrativas vigentes al día de hoy.

La pasividad administrativa respecto de las obligaciones de los servidores públicos es una de las problemáticas más arraigadas en los poderes públicos particularmente frente a las cuestiones que plantean los particulares con la legítima expectativa de obtener una respuesta. En este sentido se exige un análisis profundo del régimen de actuación reconsiderando como medida preventiva la propia identificación de las responsabilidades administrativas pertinentes en relación con el cumplimiento de obligaciones procedimentales concretas y ciertas. La resolución del procedimiento administrativo debe plantearse más allá del simple cauce de actuación, es la formulación de un conjunto de principios que simplifican el trabajo administrativo y garantizan a los ciudadanos el persecución de los fines que las Administraciones públicas tienen encomendados. El procedimiento administrativo puede observarse como la expresión jurídica de un modelo preventivo de la corrupción. Bajo estos presupuestos, la corrupción encontraría un límite importante al permitir al ciudadano exigir la consecución del procedimiento en la confianza de ser éste un fiel representante y testigo como exteriorización de la actuación administrativa.

\section{FUENTES}

BIBLIOGRÁFICAS

AGUADO I CUDOLÀ, Vicenç y CAMINO PONS, Pere. "El codi de conducta i el règim disciplinari a l'Estatut Basic de l'Empleat Públic i el seu desplegament a la legislació catalana de funció pública" en Comentaris al règim estatutari dels empleats públics, Escola d'Administració pública de Catalunya, Barcelona, 2009.

ANDRADE S. Eduardo, “Artículo $8^{\circ}$ Constitucional”, Derechos del pueblo mexicano, México a través de sus constituciones, H. Cámara de Diputados, Tomo II, México, 1985

BURRUEL HUERTA, Leopoldo, La responsabilidad del Estado y sus agentes, Porrúa-ELD, México, 2009.

ANDRADE S. Eduardo, “Artículo $8^{\circ}$ Constitucional”, Derechos del pueblo mexicano, México a través de sus constituciones, H. Cámara de Diputados, Tomo II, México, 1985

CARRO FERNÁNDEZ-VALMAYOR, José Luis, "Ética pública y normativa administrativa”, Revista de Administración Pública, No. 181, 2010.

DELGADILLO GUTIÉRREZ, Luis Humberto, El sistema de responsabilidades de los servidores públicos, Porrúa, México, 2005.

FERNÁNDEZ FARRERES, Germán. "Los códigos de buen gobierno de las Administraciones públicas", Administración y ciudadanía: Revista de la Escuela Gallega de Administración pública, Vol. 2, No. 2, 2007.

FERNÁNDEZ RUIZ, Jorge, "La dirección de responsabilidades y sanciones de la contraloría general del Departamento de Distrito Federal es autoridad de facto", Anuario Jurídico, Nueva Serie, México, 1996. 
Panorama del Derecho mexicano. Derecho Administrativo, UNAMMcGrawHill, México, 1997.

GÓNGORA PIMENTEL, Genaro David, "El afectado en forma directa o indirecta por la conducta del servidor público respecto de quien haya interpuesto queja administrativa, tiene interés jurídico para promover juicio de amparo contra la resolución que la declara improcedente o sin efectos para fincar su responsabilidad (a manera de propuesta)", Lex Difusión y Análisis, Año XI, No. 128, febrero de 2006.

MALARET I GARCIA, Elisenda, "L'Estatut bàsic de l'empleat públic: un marc legal coherent amb l'Estat autonòmic, una caixa d'eines per a la modernització administrativa", en Comentaris al règim estatutari dels empleats públics, Escola d'Administració pública de Catalunya, Barcelona, 2009.

MALUQUER DE MONTES BERNET, Carlos J., "Los códigos de conducta como fuentes del derecho", Derecho privado y Constitución, No. 17, 2003.

MARTÍ CAPITANACHI, Luz del Carmen, "La responsabilidad administrativa de los servidores públicos. Reforma constitucional en proceso", Letras Jurídicas, Año 7, No. 14, julio diciembre de 2006.

MÁRQUEZ, GÓMEZ, Daniel, Los procedimientos administrativos materialmente jurisdiccionales como medios de control en la Administración pública, UNAM, México, 2003.

MÁRQUEZ RÁBAGO, Sergio R., "Los tipos de responsabilidad del servidor público y la responsabilidad constitucional, en Lex. Difusión y análisis. Cuarta época, Año, XV, No. 183, septiembre de 2010.

MENDOZA LÓPEZ, Alberto, MORENO GARCÍA, Alfonso, ACEVO ANONALES, Dante,"Las responsabilidades administrativas de los servidores públicos", Bien Común, Año XI, No. 125, mayo de 2005.

PARADA VÁZQUEZ, Ramón, Derecho del empleo público, Marcial Pons, Madrid, 2007.

SERRANO SÁNCHEZ, Jesús Antonio, "La política oficial de combate a la corrupción en México: una revisión”, Andamios, Vol. 6, No. 12, 2009.

TORRES ULLOA, Héctor Samuel, "Responsabilidades de los servidores público. Su situación actual y perspectivas", Revista de los Tribunales Agrarios, $2^{\mathrm{a}}$ época, Año IV, No. 41, enero-abril de 2007

VILLORIA MENDIETA, Manuel, "Evaluación de las políticas y prácticas sobre los conflictos de intereses: un informe comparativo", Administración y Ciudadanía: Revista de Escola Galega de Administración Pública, Vol. 1, No. 1, 2006 